\title{
Attitudes towards human papillomavirus vaccination: a qualitative study of vaccinated and unvaccinated girls aged 17-18 years
}

\author{
Kate Williams, Alice Forster, Laura Marlow, Jo Waller
}

Department of Epidemiology and Public Health, Cancer Research UK Health Behaviour Research Centre, University College

London, London, UK

\section{Correspondence to}

Dr Jo Waller, CRUK Health Behaviour Research Centre, Department of Epidemiology and Public Health, UCL,

1-19 Torrington Place, London WC1E 6BT, UK;

j.waller@ucl.ac.uk

Received 9 June 2010

Accepted 29 September 2010

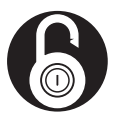

\section{OPEN ACCESS}

\section{Abstract}

Background and methodology This study explored knowledge about human papillomavirus (HPV) and attitudes towards HPV vaccination among girls who were part of the 'catch-up' vaccination programme. Interviews were carried out between March and May 2009 with girls (aged 17-18 years) who had received HPV vaccine $(n=5)$ and girls who had opted not to receive HPV vaccine $(n=5)$. Interviews lasted approximately 25 minutes, were recorded and transcribed verbatim. The data were analysed qualitatively using framework analysis.

Results Most girls were aware that HPV is sexually transmitted, but beyond this had limited understanding of HPV and HPV vaccination, and expressed a desire for further information. Girls were uncertain about the need for the vaccine both in terms of perceived risk (e.g. because they were not sexually active) and because of its novelty. Some had concerns about the efficacy and safety of the vaccine, while others were mistrusting of the information provided. Being embarrassed about discussing the vaccine with parents and practical barriers to vaccination were also discussed. Discussion and conclusions Understanding of HPV was poor, despite participants having been offered the vaccine. Schoolbased interventions might be a useful supplement to leaflets, and should focus on improving knowledge of HPV and awareness of the purpose of HPV vaccination.

\section{Introduction}

Human papillomavirus (HPV) vaccination is now available in the UK for girls in school Year 8 (aged 12-13 years). A one-off 'catch-up' programme has offered the vaccine to girls who were aged 14-18 years old when the programme began. By September 2009, 88\% of Year 8 girls had initiated the vaccination series, ${ }^{1}$ but initiation in the 'catch-up' cohort was much lower (62\%). HPV is sexually transmitted ${ }^{2}$

\section{Key message points}

- Girls had limited knowledge of human papillomavirus (HPV) and HPV vaccination and appeared to be making uninformed decisions.

- Girls were uncertain about the need for vaccination, were concerned about its novelty and some mistrusted the information provided to them.

- Girls may benefit from school-based interventions to ensure that they can make informed decisions about having the $H P V$ vaccination.

and the sexually transmitted nature of the virus may be more salient for girls in the 'catch-up' group as they are likely to be closer to sexual debut than those in the main programme.

Little is known about HPV knowledge and attitudes among British girls aged over 16 years who are expected to provide consent for the vaccine themselves. This pilot study examined knowledge about HPV and attitudes towards HPV vaccination among girls in the 'catch-up' age range using qualitative methods. It was conducted to identify themes that may be important in girls' vaccination decisions and would need exploring in a larger study.

\section{Methods}

Purposive sampling was used to recruit girls who had received at least one dose of the HPV vaccine (none had completed the series as the programme had just began) and girls who had opted not to receive the vaccine. All participants were aged 17-18 years (Year 13) and had been offered the HPV vaccine as part of the 'catch-up' programme.

Recruitment occurred at a state further education college and a state school. In the college, students were approached by a researcher and invited to take part in faceto-face interviews. Around 100 willing girls completed a demographics questionnaire (approximately 90 girls had begun the 
vaccine course and 10 had opted not to receive the vaccine). Only one girl who had not received the vaccine agreed to be interviewed but five vaccinated girls were recruited. To fulfil our sample of unvaccinated girls, we approached a school that was able to identify five Year 13 girls (out of approximately 90) who had not been vaccinated, four of whom agreed to be interviewed. These girls had been offered school-based vaccination whereas girls at the college had been invited to make an appointment with their general practitioner (GP).

Interviews lasting 15-30 minutes were carried out by one of the authors (KW) at the participants' school or college between March and May 2009 and were structured around a topic guide adapted from a previous study. ${ }^{3}$ Girls were asked about their knowledge of cervical cancer and HPV, their own and friends' experiences of and attitudes towards the HPV vaccine, and their decision to have it or not. A topic guide was used to structure the interviews. This was developed by the authors using their previous experience of carrying out similar research with parents, and with reference to the literature from other countries on HPV vaccine decision-making in this age group.

Interviews were recorded and transcribed verbatim. Data were analysed using Framework Analysis, a matrix-based approach to organising qualitative data. The themes were decided upon based on discussion between all of the authors.

\section{Results}

The analysis focused on two main themes: knowledge about HPV and cervical cancer, and attitudes towards HPV vaccination. Participant demographics are presented in Table 1.

\section{Knowledge about HPV and cervical cancer}

Overall, girls' knowledge of HPV was surprisingly limited given that they had all been offered the vaccine and most had received an information leaflet. As the vaccine is being promoted as a cervical cancer vaccine, some had not even heard of HPV. Those who had heard of HPV did not know much about it, and there was poor understanding of the causal link between HPV and cervical cancer. However, when prompted about the link between HPV and cervical cancer, some girls were able to remember basic details about it. Several girls were aware that the HPV vaccine should be given prior to sexual debut, although some thought this meant they should not have sex between each dose. Some held misconceptions about the protective effect of condoms and for that reason had a low perceived risk of HPV: "I'm not in a rush to get it because I don't have as many sexual partners or anything like that. I use protection" (NV10). [NB. Participant ID numbers distinguish between those who had been vaccinated (V) and those who had not (NV)]. Girls did not consider their lack of knowledge to be unusual; one girl mentioned that her friend had misconceptions about who the vaccine was for: "my friend kept saying that it's for people who have promiscuous sex" (V5).

Some did not understand the need for the vaccine: "I don't really know why suddenly they want us to have it [the HPV vaccine]. If people have never had it, like why introduce a new jab? I don't understand" (NV8). Furthermore, regardless of vaccine status, the girls did not think that they were at high risk of getting cervical cancer and certainly not at a greater risk than anyone else. Only one girl related her perceived risk of cervical cancer to having the HPV vaccine. She said: "I never really felt at risk but I think having it [the HPV vaccine] makes me feel more protected" (V3).

Desire for information

Most girls had received a leaflet about HPV and the vaccine when they were invited to have the vaccine. Several girls had also done their own research and some had seen stories about the HPV vaccine on the news, posters or adverts on TV. However many did not feel they had been given enough information to make an informed decision: "there was no number or email address. I wanted to get information on it but I wanted, like, a proper booklet that I could read through" (NV9).

Table 1 Sample characteristics

\begin{tabular}{llllll}
\hline Participant number* & Age (years) & HPV vaccinated? & Where was the vaccine offered? & Nationality/ethnicity & Religion \\
\hline V1 & 17 & Yes (2 doses) & GP & British Asian \\
V2 & 17 & Yes (2 doses) & GP & White British & Muslim \\
V3 & 17 & Yes (2 doses) & GP & White British & None \\
V4 & 17 & Yes (2 doses) & GP & White British & None \\
V5 & 18 & Yes (2 doses) & GP & British Asian & Muslim \\
NV6 & 18 & No & School & White British & White British \\
NV7 & 17 & Only 1 dose ${ }^{\dagger}$ & School & White British & None \\
NV8 & 18 & No & School & White British & None \\
NV9 & 18 & No & School & White British & None \\
NV10 & 18 & No & GP &
\end{tabular}

*Participant ID numbers indicate whether girls had been vaccinated (V) or not vaccinated (NV).

${ }^{\dagger}$ Not intending to complete the course.

GP, general practitioner; HPV, human papillomavirus. 
Another girl felt that the leaflet was a "patronising little bit of information" (NV10). Almost all of these girls said that they would like to have been given information on the vaccine in school. For example, one girl suggested that it would be useful to have "a lesson or like 15 minutes in assembly" (NV7). Another girl said she thought the school should "hold compulsory workshops" (V1).

\section{Attitudes towards HPV vaccination}

Five subthemes emerged relating to girls' attitudes towards HPV vaccination: (1) peers' opinions, (2) deciding to have the vaccine and discussing it with others, (3) practical issues, (4) issues relating to sexual behaviour and (5) safety and efficacy of the vaccine.

\section{Peers' opinions}

Several girls had friends who had raised concerns about the HPV vaccine. This was mainly because of a fear of needles and having to have three doses; however, one girl mentioned that her friend was concerned about the safety of the vaccine. Most felt that their friends were happy to have the vaccine and believed that having the vaccine was the norm. Some girls, particularly those who had not had the vaccine said that they knew people who did not want it. For example, one girl said some people did not see the point of having the vaccine if it only protects against one type of cancer. Another girl who had not had the HPV vaccine said that a lot of her friends did not want the vaccine but were having it because their parents wanted them to: "it was more like, 'oh, my parents think I should have it so that's why I'm having it. I really don't want to have it"” (NV10).

Deciding to have the vaccine and discussing it with others

All of the girls said they made their own decision about whether or not to have the HPV vaccine. For those who had received it, their main reason was protection against cancer. Most girls had discussed the vaccine with others. Some reported that their mothers encouraged them to have the vaccine whereas other parents were less positive. One girl reported that her mother had concerns but was more positive after she had researched it herself (V3).

\section{Issues relating to HPV and sexual behaviour}

Most girls felt that the sexually transmitted nature of HPV was not relevant to their attitudes, for example one girl said that: "More people focused on the cancer things rather than the STIs" (V3). However, one girl thought that this link could be more of an issue for younger girls because it might imply that they are having sex at a young age: "... people might think 'oh, why are you getting it done then?' and then questions will be asked" (NV6).

The issue of embarrassment was raised, in relation to the vaccine being for a sexually transmitted infection. One girl thought that some people might be embarrassed going to have the vaccine. Another said she was too embarrassed to talk about the vaccine with her father.

When prompted, most girls did not think that the HPV vaccine would encourage risky sexual behaviour. However, the opinion was expressed that some girls would "definitely feel they're more protected. Like, they won't be as worried because they'll feel they've had the jab, they've got a bit of protection" (V5).

Safety and efficacy of the vaccine

The majority of girls who had opted not to have the HPV vaccine had concerns about its novelty, efficacy and safety. For example, one girl felt that there was no evidence of the vaccine's efficacy and there was some mistrust of the information provided: "they fail to mention some certain side effects" (NV10). One girl who had received the vaccine also expressed concern about the vaccine's safety, suggesting that there were "major things that could go wrong in a few years' time" (V3).

\section{Practical issues}

Some girls who had received the vaccine highlighted practical issues. For example, one girl mentioned that she "had ... to take a couple of lessons off so [she] could go" (V3). However, in general none of them found these issues particularly problematic. In contrast, one girl (NV7) had received her first dose of the vaccine in school but was ill when the vaccination team came to administer the second dose. This girl did not prioritise arranging the second dose through her GP and consequently did not believe that she would finish the vaccination course.

\section{Discussion}

This small pilot study explored knowledge of HPV and attitudes towards HPV vaccination among girls in the first year of the HPV vaccination 'catch-up' programme who had started their HPV vaccination course or had opted not to receive it.

Knowledge of HPV and the HPV vaccine was limited, with some girls knowing nothing and few understanding the relationship between HPV and cervical cancer. This finding is reflective of the experience in adolescent vaccination generally, ${ }^{4}$ although it is still surprising, as most girls in this study had received information about HPV. Simply providing a leaflet about the vaccine appears not to be sufficient to ensure HPV knowledge. This is concerning because good knowledge is a prerequisite for informed choice. ${ }^{5}$ Furthermore, vaccinated girls who have misunderstood the purpose of the vaccine may engage in more risky sexual behaviour. There was unanimous agreement about the need for education sessions.

Some unvaccinated girls had misconceptions about the link between HPV and sexual behaviour and did not perceive a need for vaccination, or believed that they were at low risk of cervical cancer or HPV. Most girls did not think they would change their sexual behaviour as a result of having the vaccine, but they believed others might do this and some felt that talking 
about it could be embarrassing. Another reason for non-acceptance was concern about side effects.

Some participants were mistrusting of the information provided to them and believed that negative consequences of vaccination were being withheld. Parents' hesitations were reported, but social norms also promoted uptake. This demonstrates that even though these girls could provide consent themselves, they were still influenced by their parents' and others' opinions.

These findings are based on a small sample and all participants were in full-time education. It is likely that attitudes and barriers may differ from those who are not studying. Nevertheless, the findings highlight areas for further study.

In summary, both vaccinated and unvaccinated girls had a poor understanding of HPV and the HPV vaccine and wanted further information. School-based interventions could supplement information leaflets to ensure that vaccination decisions are informed and should focus on improving knowledge of HPV and raising awareness of the efficacy and safety of HPV vaccination.

Acknowledgements The authors would like to thank the girls who took part and Strode's College and Chaucer Technology School for helping with recruitment.

Funding The authors are grateful for funding from Cancer Research UK for participant payments. JW and LM have received travel funding or honoraria from Sanofi Pasteur MSD and GlaxoSmithKline, both of which manufacture HPV vaccines. JW and LM are funded by Cancer Research UK. AF receives a Dean's PhD studentship from University College London Medical School and KW received a Medical Research Council studentship for her Master's degree.
Competing interests None.

Ethical approval The study was approved by the University College London

Research Ethics Committee.

Provenance and peer review Not commissioned; externally peer reviewed.

Open Access This is an Open Access article distributed in accordance with the Creative Commons Attribution Non Commercial (CC BY-NC 4.0) license, which permits others to distribute, remix, adapt, build upon this work non-commercially, and license their derivative works on different terms, provided the original work is properly cited and the use is non-commercial. See: http://creativecommons.org/licenses/by-nc/4.0/

\section{References}

1 Department of Health. HPV Vaccination Programme: Provisional data, as submitted by PCTs, for First, Second and Third dose vaccine uptake, for the month ending 31 August 2009. 2008. http://www.immunisation.nhs.uk/publications/ HPV_VaccineUptake_Aug2009.pdf [accessed 14 September 2010].

2 Winer RL, Hughes JP, Feng Q, et al. Condom use and the risk of genital human papillomavirus infection in young women. N Engl J Med 2006;354:2645-2654.

3 Waller J, Marlow LA, Wardle J. Mothers' attitudes towards preventing cervical cancer through human papillomavirus vaccination: a qualitative study. Cancer Epidemiol Biomarkers Prev 2006;15:1257-1261.

4 Slonim AB, Roberto AJ, Downing CR, et al. Adolescents' knowledge, beliefs, and behaviors regarding hepatitis B: insights and implications for programs targeting vaccine-preventable diseases. J Adolesc Health 2005;36:178-186.

5 Cooper Robbins SC, Bernard D, McCaffery K, et al. "Is cancer contagious?": Australian adolescent girls and their parents: making the most of limited information about HPV and HPV vaccination. Vaccine 2010;28:3398-3408. 

vaccination: a qualitative study of vaccinated and unvaccinated girls aged $17-18$ years

Kate Williams, Alice Forster, Laura Marlow and Jo Waller

J Fam Plann Reprod Health Care 2011 37: 22-25

doi: 10.1136/jfprhc.2010.0017

Updated information and services can be found at:

http://jfprhc.bmj.com/content/37/1/22

References

Open Access

\section{Email alerting service}

\section{These include:}

This article cites 4 articles, 1 of which you can access for free at: http://jfprhc.bmj.com/content/37/1/22\#BIBL

This is an Open Access article distributed in accordance with the Creative Commons Attribution Non Commercial (CC BY-NC 4.0) license, which permits others to distribute, remix, adapt, build upon this work non-commercially, and license their derivative works on different terms, provided the original work is properly cited and the use is non-commercial. See: http://creativecommons.org/licenses/by-nc/4.0/

Receive free email alerts when new articles cite this article. Sign up in the box at the top right corner of the online article.

\section{Topic Articles on similar topics can be found in the following collections Collections Open access (27)}

\section{Notes}

To request permissions go to:

http://group.bmj.com/group/rights-licensing/permissions

To order reprints go to:

http://journals.bmj.com/cgi/reprintform

To subscribe to BMJ go to:

http://group.bmj.com/subscribe/ 